\section{Characterization and selection of interspecific hybrids of Brachiaria decumbens for seed pro- duction in Campo Grande - MS}

\section{Lenise Castilho Monteiro' ${ }^{1}$, Jaqueline Rosemeire Verzignassi ${ }^{2}$, Sanzio Carvalho Lima Barrios ${ }^{2}$, Cacilda Borges do Valle ${ }^{2}$, Celso Dornelas Fernandes ${ }^{2}$, Gleiciane de Lima Benteo ${ }^{1}$ and Cláudia Barrios de Libório ${ }^{1}$}

\begin{abstract}
The breeding program Brachiaria developed by Embrapa Beef Cattle provides studies to obtain forage with agronomic characters desired by farmers. In this regard, in 2013 and 2014, a study was carried out in order to select the best Brachiaria decumbens intraspecific hybrids, which are superior in relation to production, forage nutritional value, and resistance to spittlebugs. Estimates of genetic parameters and gains with selection were carried out. It was found that there was significant variability between genotypes for all characters. Gain with selection (GS\%) ranged from 12 to $324 \%$, and the highest percentage was found for weight of pure seeds (PS) of seed collectors of the second harvest. For reproductive tillers (RT), COO1 and R091 hybrids had better performance than the control, and this character may be considered as a parameter to estimate production of pure seeds before flowering starts.
\end{abstract}

Key words: Seed production potential, genetic variability, genotypes, forage improvement.

\section{INTRODUCTION}

At first, selection of forage plants was based only on mass production potential and on forage quality under pasture conditions. However, in recent years, some changes have been observed in strategies of breeding programs of these plants, aiming at obtaining superior cultivars in all aspects. Cultivars development process is long, comprising several stages, and the evaluated characters should be correlated in order to result in crops that have good performance at all stages and variables of study and research. In order to reach the release of a new cultivar, the development process involves several research lines, such as improvement; cytogenetics of the reproductive system; plant nutrition; microbiology; plant health; pasture management and nutritional quality of plants; and seed production and technology, among others (Karia et al. 2006, Valle et al. 2009).

Improvement of tropical forage plants is relatively new compared to other cultures (Karia et al. 2006, Araújo et al. 2008, Valle et al. 2009), and aims to release more productive plants in production and forage quality, and in various agronomic aspects, such as production of good quality seeds and in satisfactory quantity, adaptation to different soil and climate conditions, and especially
Crop Breeding and Applied Biotechnology 16: 174-181, 2016 Brazilian Society of Plant Breeding. Printed in Brazil http://dx.doi.org/10.1590/198470332016v16n3a27 
resistance to spittlebug.

Brachiaria plants have been widely used as forage in tropical America, and most species found in Brazil are considered exotic. Recently, there has been a reclassification of the Brachiaria genus to Urochloa. However, discussions remain among researchers regarding its characteristics and new taxonomic classification. Brachiaria decumbens, for its high forage production potential and high adaptability to acid soils and of low fertility, has great importance for national beef cattle. Even being economically very relevant, there is only one cultivar in the market, cv. Basilisk, which was released in the 1960s. One of the limitations of this cultivar is its susceptibility to spittlebugs.

It is extremely important that cultivars from breeding programs solve problems such as susceptibility to spittlebugs. Cv. Marandu is an example, which has been available since the 1980s. A few options of cultivars available to producers have good seed production, so that the ratio production cost $x$ price of seed production is satisfactory. Seed production may vary depending on the location of production, management, and on the form of harvest, and it may reach up to $300 \mathrm{~kg} \mathrm{ha}^{-1}$ (Monteiro et al. 2016).

This work aims to characterize and evaluate the potential of seed production by intraspecific hybrids of Brachiaria decumbens, developed and pre-selected by the breeding program of Embrapa Beef Cattle, aiming at selecting superior genotypes, which could be candidates for new cultivars or potential parents of sexual propagation to be used in new crosses.

\section{MATERIAL AND METHODS}

Genetic materials used in the development of this work were selected based on previous experimental results obtained by the Forage Cultivars Breeding and Production Program of Embrapa Beef Cattle. Promising intraspecific hybrids of Brachiaria decumbens (sexual and apomictic), parents and candidates for new cultivars were selected among 324 hybrids, which were obtained by crossing between three plant of sexual reproduction of $B$. decumbens artificial tetraploids (D24/2, D24/27 e D24/45) with cv. Basilisk (apomictic). Selection was based on agronomic characteristics of production, forage nutritional value, and resistance to spittlebugs. $B$. brizantha $\mathrm{cv}$. Marandu was used as control. Table 1 shows the genotypes evaluated during the first (2013) and the second (2014) harvest.

Trials were carried out for two consecutive years in Campo Grande - MS, at Embrapa Beef Cattle (lat 20 25' $03^{\prime \prime} \mathrm{S}$, long $54^{\circ} 42^{\prime} 20^{\prime \prime} \mathrm{W}$, alt $530 \mathrm{~m}$ asl). Local climate is classified as Aw tropical rainy savanna, characterized by rainy summer and dry winter. Trials were carried out under normal environmental conditions, in rainy condition. Soil was classified as clayey dystroferric Red Latosol (Oxisol) ( $53 \%$ clay, $38 \%$ sand and silt $9 \%$ ).

Plants were transferred to the field in early 2012 in the

Table 1. Genotypes evaluated during the first and the second years of production

\begin{tabular}{|c|c|c|c|}
\hline Genotypes & 1st year & 0 & 2nd year \\
\hline A001 & A036 & & B006 \\
\hline A002 & A038 & & C001 \\
\hline A003 & A041 & & R025 \\
\hline A004 & $\mathrm{A} 042$ & & R033 \\
\hline A005 & A043 & & R041 \\
\hline A007 & A044 & & R044 \\
\hline A008 & B005 & & R071 \\
\hline A009 & B009 & & R078 \\
\hline A011 & B010 & & R087 \\
\hline A012 & B026 & & R091 \\
\hline A013 & C001 & & R101 \\
\hline A015 & R184 & & R107 \\
\hline A017 & S044 & & R110 \\
\hline A018 & T038 & & R120 \\
\hline A019 & X121 & & R124 \\
\hline A020 & - & & R126 \\
\hline A021 & - & & R144 \\
\hline A023 & - & & R181 \\
\hline A024 & - & & S018 \\
\hline A025 & - & & S031 \\
\hline A026 & - & & S036 \\
\hline A027 & - & & T005 \\
\hline A028 & - & & T012 \\
\hline A029 & - & & T026 \\
\hline A030 & - & & T054 \\
\hline A031 & - & & X030 \\
\hline A032 & - & & X072 \\
\hline A033 & - & & X117 \\
\hline A035 & - & & Y021 \\
\hline
\end{tabular}

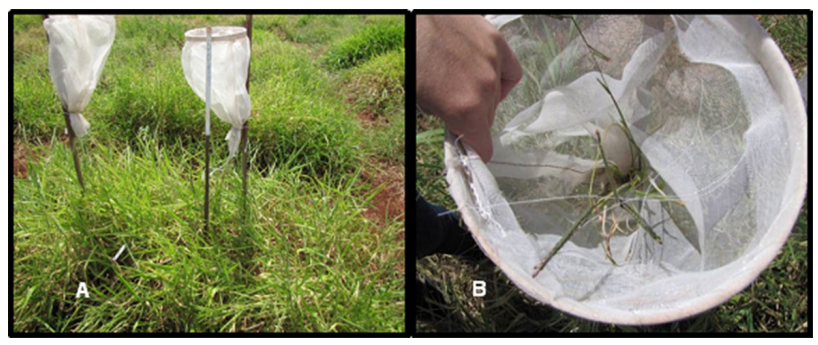

Figure 1. Seed collectors installed in the plot (A). Inflorescence inside the collector (B). 


\section{LC Monteiro et al.}

form of seedlings. Each plot contained two seedlings, with useful area of $2 \mathrm{~m}^{2}$, spaced $1 \mathrm{~m}$ between plots. Evaluations were carried out in the first quarter of 2013, with first-year plants, and between December 2013 and the first quarter of 2014, with second-year plants. For the first year of evaluations (2012/2013 crops), it was carried out uniform cutting of plants for seed production in October 2012. For the second year of evaluation, standardization was carried out on October 15, 2013. The experimental design was a complete block with two replications, and two observations per plot. After uniform cuttings (2012 and 2103), fertilization of plants was carried out based on soil chemical analysis. Evaluations were carried out in plots and in seeds collectors. Two collectors per plot were installed and, inside them, it was placed five inflorescences in complete anthesis without threshing (Figure 1).

To determine the typical inflorescences of genotype, ten inflorescences selected at random were collected. When at least six of them were of the same type, it was considered typical inflorescence. Eight typical inflorescences were collected in each plot, and from them, the following characteristics were determined: number of seeds per raceme (NSR), number of racemes (NR), number of seeds per inflorescence (NSI), length of racemes (LR), and length of inflorescences (LI). To determine these characteristics, it was carried counting in increasing order from the inflorescence base to the apex. LR was determined with the aid of a graduated scale. To this end, each raceme was measured from its insertion point in the rachis to the apex. LI was obtained with the aid of the graduated scale, by measuring the distance between the insertion point of the first and last raceme in the inflorescence.

It was also carried out evaluations in the plots at the beginning of the formation of the first reproductive tillers, and before the formation of the first panicle (inflorescence), in $0.25 \mathrm{~m}^{2}$ in relation to the number of reproductive tillers (RT). After threshing of inflorescences' seeds, collectors were removed from the plots with their respective seeds and flowers. The collected material was taken to the Seed Laboratory of Embrapa Beef Cattle and evaluated for weight of pure seeds (PS) and weight of empty seeds (ES).

To determine the quality of seeds, it was carried out harvest of the total area of the plot $\left(2 \mathrm{~m}^{2}\right)$. To this end, in the maturation point of each plot, it was carried out plant cutting of the entire plot (except the inflorescences that were inserted in the collectors). Cutting was carried out manually at $20 \mathrm{~cm}$ from the soil, with a rice cutter, and was carried out at the beginning of threshing, of 15 to $20 \%$ of inflorescences' seeds. The material collected was packed in paper bags, which were closed and placed to dry in the shade. After drying, samples were submitted to manual separation of inflorescences' seeds. Seeds were then subjected to processing by pre-cleaning and cleaning using mesh and air column blower. After seeds processing, which were harvested in 2013, it was carried out the germination standard test (G\%), according to RAS (Seed Analysis Rules) (Brasil 2009).

The collected data were submitted to analysis of deviance (ANADEV) using the Selegen-Reml/Blup software (Resende 2006) in order to simultaneously estimate genetic parameters and predict breeding values (BLUP). For the evaluations carried out in 2013, it was used the model of the 20 Selegen-Reml/Blup software, as follows:

$$
\mathrm{y}=\mathrm{Xr}+\mathrm{Zg}+\mathrm{e}
$$

In which $y$ is the data vector; $r$ is the vector of replication effects (fixed) added to the mean; $g$ is the vector of genotypic effects (random); e is the error vector or residues (random); $\mathrm{X}$ and $\mathrm{Z}$ are the incidence matrices for these effects. For the other characters, evaluated in 2014, it was used the model 2 of the software, as follows:

$$
\mathrm{y}=\mathrm{Xr}+\mathrm{Zg}+\mathrm{Wp}+\mathrm{e}
$$

In which $y$ is the data vector; $r$ is the vector of replication effects (fixed), added to the mean; $g$ is the vector of genotypic effects (random); $\mathrm{p}$ is the vector of plot effects; $\mathrm{e}$ is the vector error or residue (random); $\mathrm{X}, \mathrm{Z}$ and $\mathrm{W}$ are the incidence matrices for these effects.

\section{RESULTS AND DISCUSSION}

For germination percentage (G\%) of the first harvest, there was genotypic difference. Block effect, which was considered as fixed effect, was tested by the Snedecor F test. When genotype effects are significant, respective components of variance are significantly different from zero, and so are their coefficients of determination (Resende and Duarte 2007). Heritability between genotypes means $\left(h^{2} \mathrm{mc}\right)$ exceeded in $50 \%$, and it can be considered of medium magnitude, showing 
that more than half of the observed phenotypic variation, on average, was due to genetic causes (Table 2).

Of the seeds trashed in the collectors, it was observed accuracy (Acc) of 84 and $97 \%$ (Table 2). Thus, it was within the stablished standards, and was classified as high (Resende and Duarte 2007), which means good reliability for the prediction of genotypic values of treatments. Both for weight of pure seeds (PS) and for weight of empty seeds (ES), it was found significant differences by the Chi-square test (LRT) for the genotype effect, and their heritability estimates $\left(h^{2} m c\right)$ presented percentage above 0.50 (Table 2).

Table 2. Deviance Analysis (ANADEV), variation components of genetic parameters for germination (G\%) in the first harvest, weight of pure seeds (PS), weight empty seeds (ES), number of reproductive tillers (RT), number of seeds per inflorescence (NSi), number of seeds per racemes (NSR), number of racemes (NR), length of raceme (LR) and length of inflorescences (LI) in the second harvest

\begin{tabular}{|c|c|c|c|c|c|c|c|c|c|c|c|}
\hline & \multicolumn{3}{|c|}{ ANADEV } & \multicolumn{3}{|c|}{ Variation Components } & \multicolumn{5}{|c|}{ Genetic Parameters } \\
\hline & Genotypes & Plot & Blocks & Genotypes & Plot & Blocks & $h^{2} g$ & $h^{2} m c$ & Acc & General Mean & CVe (\%) \\
\hline${ }^{1} \mathrm{G} \%$ & $4.52^{*}$ & - & 1.63 & 11.93 & - & - & $0.42+-0.24$ & 0.59 & 0.77 & 10.32 & 39.06 \\
\hline${ }^{2} \mathrm{PS}\left(\mathrm{g} \mathrm{m}^{-2}\right)$ & $26.42^{* *}$ & 0.01 & 0.00 & 0.30 & $8.10^{-4}$ & 0.06 & $0.83+-0.30$ & 0.95 & 0.97 & 0.25 & 70.98 \\
\hline $\begin{array}{l}{ }^{2} \mathrm{ES}(\mathrm{g} \\
\left.\mathrm{m}^{-2}\right)\end{array}$ & $7.14^{* *}$ & 0.00 & 0.00 & 0.05 & $7.10^{-4}$ & 0.08 & $0.37+-0.20$ & 0.7 & 0.84 & 0.83 & 24.08 \\
\hline${ }^{3} \mathrm{RT}$ & $11.86^{* *}$ & 0.00 & $157.55^{* *}$ & 871.77 & 0.50 & 115.13 & $0.88+-0.31$ & 0.97 & 0.98 & 38.61 & 19.73 \\
\hline${ }^{3} \mathrm{NSI}$ & $33.24^{* *}$ & $22.98^{* *}$ & 0.05 & 1070.14 & 388.28 & 973.40 & $0.44+-0.11$ & 0.77 & 0.88 & 30.77 & 18.61 \\
\hline${ }^{3} \mathrm{NR}$ & $235.46^{* *}$ & $2667.90^{* *}$ & $250000^{* *}$ & 0.54 & 0.48 & $10^{-6}$ & $0.53+-0.12$ & 0.69 & 0.83 & 4.42 & 15.68 \\
\hline${ }^{3} \mathrm{LR}$ & $64.85^{* *}$ & $5.08^{*}$ & $224.64^{* *}$ & 5.32 & 0.47 & 3.17 & $0.59+-0.13$ & 0.89 & 0.95 & 6.23 & 18.05 \\
\hline${ }^{3} \mathrm{LI}$ & $32.02^{* *}$ & $132.55^{* *}$ & $366.99^{* *}$ & 8.16 & 4.44 & 2.33 & $0.55+-0.12$ & 0.76 & 0.87 & 11.34 & 19.77 \\
\hline
\end{tabular}

${ }^{1}$ Evaluations carried out in beds during the first harvest. ${ }^{2}$ Evaluations carried out in seed collectors during the second harvest. ${ }^{3}$ Evaluations carried out in beds during the second harvest. * Significant at the likelihood ratio test, considering $5 \%$ probability by the $\mathrm{X}^{2}$ test. ${ }^{* *}$ Significant at the likelihood ratio test, considering $1 \%$ probability by the $\mathrm{X}^{2}$ test.

Table 3. Predicted genotypic values (BLUP) of 44 hybrids (Hib) and gain with selection (GS\% at 30,20 and $10 \%$ selection intensity) for the germination $(\mathrm{G} \%)$ of $B$. decumbens hybrids in the first harvest

\begin{tabular}{|c|c|c|c|c|c|}
\hline & & & & & \\
\hline & Treatments & BLUP (LL-UL) & & Treatments & BLUP (LL-UL) \\
\hline 1 & A044 & $19.95(15.55-24.35)$ & 23 & A015 & $9.95(4.76-15.15)$ \\
\hline 2 & A029 & $13.70(9.30-18.10$ & 24 & A032 & $9.95(4.76-15.15)$ \\
\hline 3 & $\mathrm{~A} 030$ & $13.70(9.30-18.10)$ & 25 & T038 & $9.95(4.76-15.15)$ \\
\hline 4 & A004 & $13.34(8.15-18.53)$ & 26 & C001 & $9.83(5.43-14.23)$ \\
\hline 5 & A025 & $13.10(8.70-17.50)$ & 27 & A009 & $9.57(4.35-14.79)$ \\
\hline 8 & A042 & $12.49(7.30-17.69)$ & 30 & A033 & $9.53(4.33-4.72)$ \\
\hline 9 & A036 & $11.69(6.47-16.90)$ & 31 & B009 & $9.53(4.33-14.72)$ \\
\hline 10 & $\mathrm{X} 121$ & $11.69(6.47-16.90)$ & 32 & A035 & $9.24(4.84-13.64)$ \\
\hline 11 & A020 & $11.65(6.45-16.84)$ & 33 & A012 & $9.15(3.93-14.36)$ \\
\hline 12 & A008 & $11.62(7.22-16.02)$ & 34 & B005 & $9.10(3.91-14.30)$ \\
\hline 16 & A019 & $10.80(5.60-15.99)$ & 38 & $\mathrm{~A} 007$ & $8.26(3.06-13.45)$ \\
\hline 17 & A027 & $10.43(6.03-14.83)$ & 39 & A002 & $7.75(3.35-12.15)$ \\
\hline 18 & A028 & $10.37(5.18-15.57)$ & 40 & A005 & $7.41(2.22-12.60)$ \\
\hline 19 & B010 & $10.37(5.18-15.57)$ & 41 & A011 & $7.41(2.22-12.60)$ \\
\hline 20 & A021 & $10.13(5.73-14.53)$ & 42 & A018 & $7.41(2.22-12.60)$ \\
\hline 21 & A038 & $09.99(4.78-15.21)$ & 43 & A043 & $6.86(2.46-11.26)$ \\
\hline 22 & A003 & $09.95(4.76-15.15)$ & 44 & A001 & $6.14(0.95-11.33)$ \\
\hline GS\% & $30 \%$ & $20 \%$ & & & \\
\hline & 26 & 47 & & & \\
\hline
\end{tabular}

LL: Lower limit of the withdrawal period; UL: Upper limit of the withdrawal period. 


\section{LC Monteiro et al.}

Heritability of individual plots $\left(h^{2} g\right)$ takes into account the existence of only one genotype replication, while among genotypes means $\left(h^{2} \mathrm{mc}\right)$, the presence of replications assists in reducing the environmental effect (Resende and Duarte 2007), contributing to higher $h^{2}$ mc estimates. Coefficient of variation (CVe) was considered as low for the characters, except for weight of pure seeds (PS), which was $70.98 \%$

For evaluations carried out in beds, accuracy of the morphological characterization of the inflorescence ranged from 83 to $91 \%$. It is considered satisfactory and is classified of high magnitude (Resende and Duarte 2007). Heritability of individual plots $\left(h^{2} g\right)$ for number of seeds in the inflorescences (NSI) and number of seeds per racemes (NSR) did not exceed 0.50. Broad sense heritabilities $\left(h^{2} m c\right)$ were 0.77 and 0.82 , respectively.

For the number of reproductive tillers (RT), number of racemes (NR), length of raceme (LR) and length of inflorescences (LI), heritability of individual plots $\left(h^{2} g\right)$ and broad sense heritability $\left(h^{2} m c\right)$ were greater than 0,50 . Genotypic and plot effects were significant for all characters, except for number of seeds per raceme (NSR), which showed no difference in the plot effect. Estimates of heritability between genotypes means $\left(h^{2} m c\right)$ showed high magnitude, exceeding 0.50 (Table 2). From the predicted breeding values (BLUP), it is possible to obtain the ranking of hybrids for each character, and to reliably identify hybrids with superior genotypic values (Resende 2006).

For evaluations during the first year, hybrid A044 was ranked in the first position for $\mathrm{G} \%$, differing from the other hybrids, when the confidence interval is observed. The range of BLUP values was high, from 19, 95 for the first ranked, to 6.14 , for the last ranked; thus, variation was of $70 \%$. Gain with selection (GS\%), at $30 \%, 20 \%$ and $10 \%$ of selection intensity, in relation to the population mean, ranged from 26 to $47 \%$. It should be noted that the higher the gain with selection in relation to the population mean, the greater the progress in the selection of superior genotypes (Table 3).

For evaluations carried out in seeds collectors during the second harvest, both for weight of pure seeds (PS) and for weight of empty seeds (ES), control cv. Marandu presented the highest genotypic values (BLUP). Low production of pure seed of the genotypes may be inherited by the next generation, since both the narrow-sense heritability $\left(h^{2} g\right)$

Table 4. Predicted genotypic values (BLUP), (GS\% at 30, 20 and $10 \%$ selection intensity) regarding weight of pure seeds (PS) and weight of empty seeds (ES) in relation to cv. Marandu (Mar) for $B$. decumbens hybrids evaluated in seed collectors in the second harvest

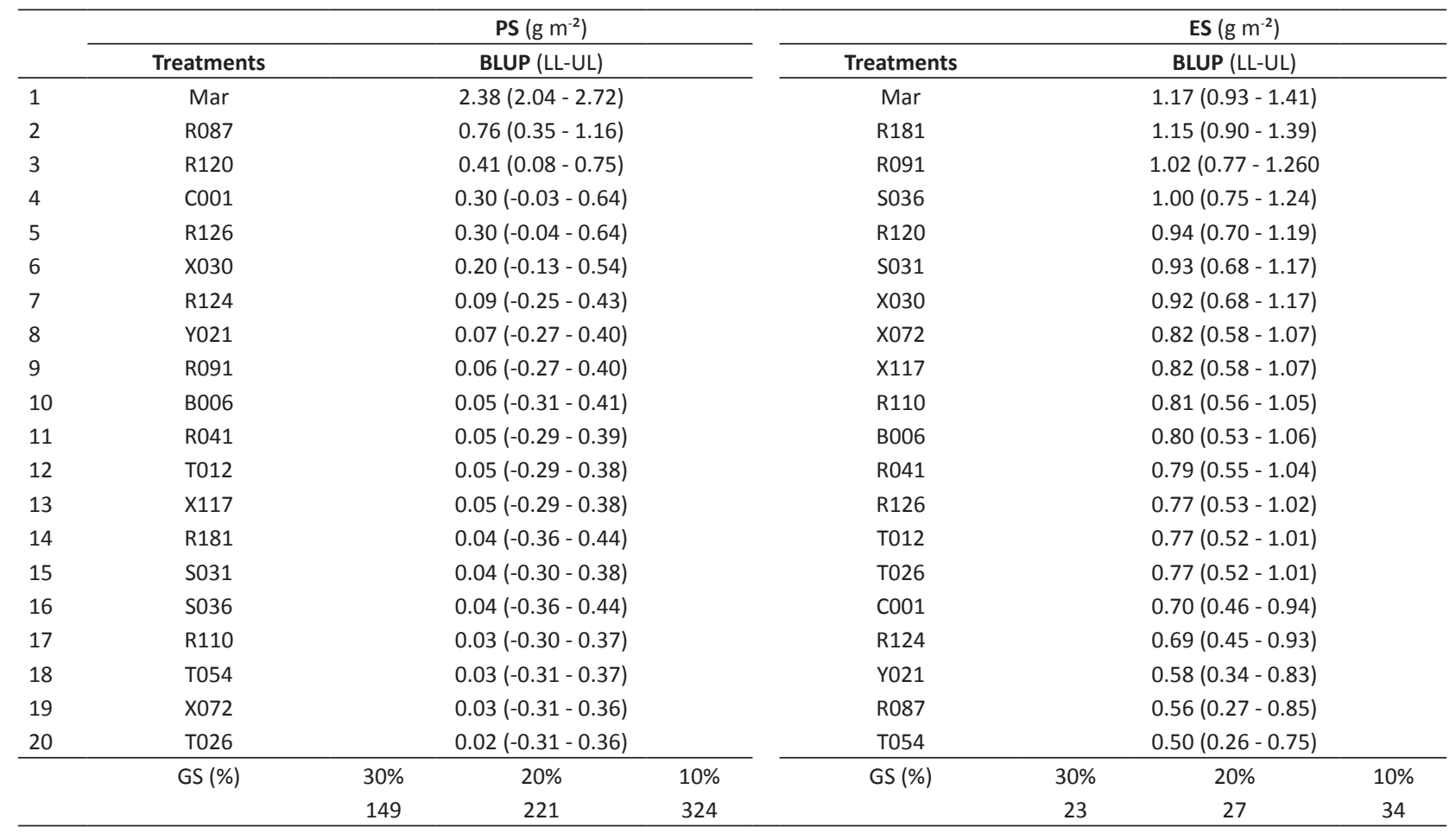

LL: Lower limit of the withdrawal period; UL: Upper limit of the withdrawal period. 
Table 5. Predicted genotypic values (BLUP) and gain with selection (GS\% in 30, 20 and $10 \%$ selection intensity) in relation to the number of reproductive tillers (RT), number of seeds per inflorescence (NSI), number of seeds per raceme (NSR) and number of racemes (NR) compared to the treatments (Treat) Cv. Marandu (Mar) and B. decumbens hybrids evaluated in the beds in the second harvest

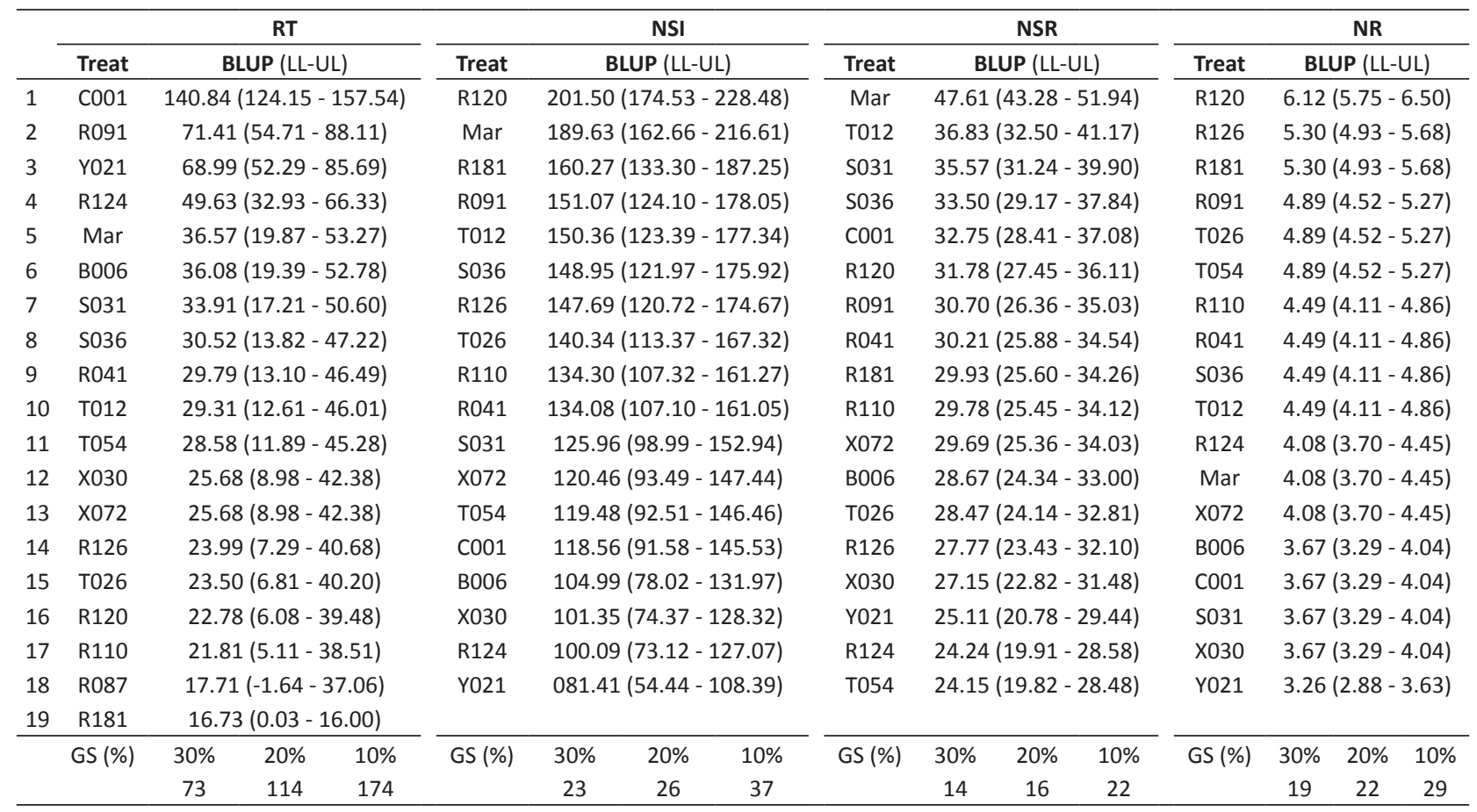

LL: Lower limit of the withdrawal period; UL: Upper limit of the withdrawal period.

and the broad-sense heritability $\left(h^{2} m c\right)$ were of high magnitude (Table 2). For PS, gains with selection (GS\%) at 30, 20 and $10 \%$ of selection intensity were respectively 149, 221 and 324\%; and for ES, it was 23,27 and 34\%, compared to population means (Table 4).

Weight of pure seeds (PS) of the hybrids was, in general, of low magnitude than that of control (Table 3). Three factors may have contributed to this: the high abortion rate in function of hybridization, as suggested by Lutts et al. (1991); the interference by spittlebugs infestation; and the possibility of being a characteristic of the genotype, producing only vegetative tillers, and only under extreme stress conditions it would produce reproductive tillers.

Non-viability of hybrid seeds may be caused by environmental interference, affecting the viability of pollen. Also, it could happen for the hybrid's genotype present gametophytic incompatibility allele, and thus blocking endosperm formation, and consequently seed filling.

Mateus et al. (2015) evaluated B. decumbens intraspecific hybrids, including R033, R126, R181, S036, T026 and X117, and also found high nymphal survival of spittlebugs, exceeding $60 \%$. It is noteworthy that all hybrids tested in this study were considered susceptible or mid-resistant in previous works, with spittlebug nymphal survival ranging from 44 to $90 \%$. For values above $40 \%$ nymphal survival, genotypes are not subjected to screening for genetic resistance.

For RT, cv. B. brizantha was ranked in the fifth position, differing from genotypes C001, R091 and Y021, taking into account the confidence interval. Gains with selection (GS\%) at 30, 20 and 10\% intensity were, respectively, 73, 114 and $174 \%$ (Table 5). The high potential for production of reproductive tillers has heritability of high magnitude of 0.88 and 0.97 in individual plots $\left(h^{2} g\right)$ and in the broad-sense heritability $\left(h^{2} m c\right)$, respectively. Comparing the BLUP of the morphological characters, cv. Marandu was ranked in the second, first and twelfth positions in number of seeds per inflorescence (NSI), number of seeds per raceme (NSR), and number of racemes (NN), respectively. However, the cultivar did not present better performance than R120 genotype for NSI. R120. R120, R126, R181, R091, T026, T054, R110, R041, S036, T012, and R124 genotypes showed higher BLUP in relation to the control, presenting gain in relation to the 
Table 6 Predicted genotypic values (BLUP) and gain with (GS\% at 30, 20 and 10\% selection intensity) and length of racemes (LR) and length of inflorescence (CLI) compared to cv. Marandu (Mar) B. decumbens for hybrids (Hib) evaluated in the beds in the second harvest

\begin{tabular}{|c|c|c|c|c|c|c|c|}
\hline & \multicolumn{3}{|c|}{ LR } & \multicolumn{4}{|c|}{ LI } \\
\hline & Treatments & \multicolumn{2}{|c|}{ BLUP (LL-UL) } & Treatments & \multicolumn{3}{|c|}{ BLUP (LL-UL) } \\
\hline 1 & Mar & \multicolumn{2}{|c|}{$14.87(13.38-16.36)$} & Mar & \multicolumn{3}{|c|}{$17.63(15.24-20.02)$} \\
\hline 2 & R181 & \multicolumn{2}{|c|}{$6.88(5.39-8.37)$} & $\mathrm{R} 120$ & \multicolumn{3}{|c|}{$14.63(12.24-17.02)$} \\
\hline 3 & X030 & \multicolumn{2}{|c|}{$6.57(5.08-8.06)$} & T026 & \multicolumn{3}{|c|}{$13.93(11.55-16.32)$} \\
\hline 4 & S036 & \multicolumn{2}{|c|}{6.50 (5.01 - 7.99) } & T054 & \multicolumn{3}{|c|}{$13.77(11.39-16.16)$} \\
\hline 5 & S031 & \multicolumn{2}{|c|}{$6.18(4.69-7.67)$} & R126 & \multicolumn{3}{|c|}{$13.03(10.65-15.42)$} \\
\hline 8 & T012 & \multicolumn{2}{|c|}{$5.83(4.34-7.32)$} & R041 & \multicolumn{3}{|c|}{$11.57(9.18-13.95)$} \\
\hline 9 & X072 & \multicolumn{2}{|c|}{$5.83(4.34-7.32)$} & R110 & \multicolumn{3}{|c|}{$11.33(8.95-13.72)$} \\
\hline 10 & R120 & \multicolumn{2}{|c|}{$5.79(4.30-7.28)$} & S031 & \multicolumn{3}{|c|}{$11.14(8.76-13.53)$} \\
\hline 11 & R041 & \multicolumn{2}{|c|}{$5.67(4.18-7.16)$} & R091 & \multicolumn{3}{|c|}{$10.99(8.60-13.38)$} \\
\hline 12 & T054 & \multicolumn{2}{|c|}{$5.55(4.06-7.04)$} & R124 & \multicolumn{3}{|c|}{$10.42(8.04-12.81)$} \\
\hline 16 & R126 & & & X030 & & $5.70-$ & \\
\hline 17 & Y021 & & & R181 & & $5.50-$ & \\
\hline 18 & R091 & & & Y021 & & $(3.99$ & \\
\hline & GS (\%) & $30 \%$ & $10 \%$ & GS (\%) & $30 \%$ & $20 \%$ & $10 \%$ \\
\hline & & 12 & 17 & & 22 & 26 & 30 \\
\hline
\end{tabular}

LL: Lower limit of the withdrawal period; UL: Upper limit of the withdrawal period.

number of racemes (NR). R120 genotype stood out both for number of seeds per inflorescence (NSI) and number of racemes (NR), taking the first position in the two variables of seed production. This fact may be a promising indicative for its production potential. Although the genotypes present genotypic values of high magnitude when compared with the control in NSI and NR, they had heritability in individual plots $\left(h^{2} g\right)$ inferior to 0.50 .

Cultivar Marandu, the control, was ranked in the first position for both length of racemes (LR) and length of inflorescences (LI). However, it appears that a character does not influence the other, since R120 genotype takes the second position in length of inflorescences, and its racemes have the tenth shorter length (Table 6).

\section{CONCLUSIONS}

The number of reproductive tillers presents high heritability both in the broad sense $\left(h^{2} m c\right)$ and in individual plots $\left(h^{2} g\right)$, and can be a parameter to predict seed production potential. However, it is necessary further studies on which components really influence seed production of forage plants.

The genotypes that had better performance for production of reproductive tillers (RT) and weight of pure seeds (PS) were C001 and R091.

\section{ACKNOWLEDGEMENTS}

The authors thank the Instituto Federal Goiano - Campus Rio Verde, Embrapa Beef Cattle, Fapeg, CNPq, Fundect, Unipasto, Fundapam, and the members of the Technology and Tropical Forage Seed Production Team of Embrapa Beef Cattle, especially Mr. Luiz de Jesus, Hugo Corado and Vagner Martins.

\section{REFERENCES}

Araújo SAC, Deminics BB and Campos PRSS (2008) Melhoramento genético de plantas forrageiras tropicais no Brasil. Archivos de Zootecnia 57: 61-76.
Brasil (2009) Ministério da Agricultura, Pecuária e Abastecimento: Regras para análise de sementes. Ministério da Agricultura, Pecuária e Abastecimento. Secretaria de Defesa Agropecuária. MAPA/ACS, Brasília, 399p. 
Karia CT, Duarte JB and Araújo ACG (2006) Desenvolvimento de cultivares do gênero Brachiaria (trin.) Griseb. no Brasil. Embrapa Cerrados, Planaltina, 163p.

Lutts S, Ndikumana J and Louant BP (1991) Fertility of Brachiaria ruziziensis in interspecific crosses with Brachiaria decumbens and Brachiaria brizantha: meiotic behavior, pollen viability and seed set. Euphytica 57: 267-274.

Mateus RG, Barrios SCL, Valle CB, Valério JR, Torres FZV, Martins LB and Amaral PN (2015) Genetic parameters and selection of Brachiaria decumbens hybrids for agronomic traits and resistance to spittlebugs. Crop Breeding and Applied Biotechnology 15: 227-234.
Monteiro LC, Verzignassi JR, Barrios SCL, Valle CB, Fernandes CD, Benteo GL and Libório CB (2016) Brachiaria decumbens intraspecific hybrids: characterization and selection for seed production. Journal of Seed Science 38: 62-67.

Resende MDV (2006) O software Selegen-Reml/Blup. Embrapa Gado de Corte, Campo Grande, 299p.

Resende MDV and Duarte JB (2007) Precisão e controle de qualidade em experimentos de avaliação de cultivares. Pesquisa Agropecuária Tropical 27: 182-194.

Valle CB, Jank L and Resende RMS (2009) O melhoramento de forrageiras tropicais no Brasil. Revista Ceres 56: 460-472. 